\title{
Review Article \\ Sales Forecasting for Fashion Retailing Service Industry: A Review
}

\author{
Na Liu, Shuyun Ren, Tsan-Ming Choi, Chi-Leung Hui, and Sau-Fun Ng \\ Institute of Textiles and Clothing, Faculty of Applied Science and Textiles, The Hong Kong Polytechnic University, \\ Hung Hom, Kowloon, Hong Kong \\ Correspondence should be addressed to Tsan-Ming Choi; jason.choi@polyu.edu.hk
}

Received 16 August 2013; Revised 5 October 2013; Accepted 5 October 2013

Academic Editor: Kannan Govindan

Copyright (C) $2013 \mathrm{Na}$ Liu et al. This is an open access article distributed under the Creative Commons Attribution License, which permits unrestricted use, distribution, and reproduction in any medium, provided the original work is properly cited.

\begin{abstract}
Sales forecasting is crucial for many retail operations. It is especially critical for the fashion retailing service industry in which product demand is very volatile and product's life cycle is short. This paper conducts a comprehensive literature review and selects a set of papers in the literature on fashion retail sales forecasting. The advantages and the drawbacks of different kinds of analytical methods for fashion retail sales forecasting are examined. The evolution of the respective forecasting methods over the past 15 years is revealed. Issues related to real-world applications of the fashion retail sales forecasting models and important future research directions are discussed.
\end{abstract}

\section{Introduction}

Inventory planning is a fundamental part of fashion retail operations. Proper retail inventory management, which helps to balance supply and demand, relies heavily on accurate forecast of future demand. In fact, sales forecasting refers to predicting future demand (or sales), assuming that the factors which affected demand in the past and are affecting the present will still have an influence in the future. It is an important task but is very difficult to accomplish.

In the fashion retailing industry, which is defined as the retailing business of fashion products including apparel, shoes, and fashion beauty products, forecasting itself can be treated as a "service" which represents the set of analytical tools that facilitate the companies to make the best decisions for predicting the future. Undoubtedly, a good forecasting service system can help to avoid understocking or overstocking in retail inventory planning, which further relates to other critical operations of the whole supply chain such as due date management, production planning, pricing $[1,2]$, and achieving high customer service level [3]. In order to achieve economics sustainability under a highly competitive environment, a company should adopt a consumer-demand driven "pull" operational strategy which means forecasting becomes a critically important task.

Compared to other retailing service industries, it is well argued that sales forecasting is a very difficult task in fashion retailing because fashion product's demand is highly volatile with ever-changing taste of the consumers and the fashion product's life cycle is very short $[4,5]$. In addition, the sales of fashion products are strongly affected "stochastically" by seasonal factors, fashion trend factors [6], and many tricky variables (e.g., weather, marketing strategy, political climate, item features, and macroeconomic trend). These, together with the fact that fashion retailers are carrying a large number of stock-keeping-units (SKUs) with limited historical sales data, all make sales forecasting challenging and call for more sophisticated and versatile analytical tools. On the other hand, it is known that the fashion apparel supply chain is a relatively long one which includes upstream cotton plants, fiber manufacturers, apparel factories, distributors, wholesalers, and retailers. As a consequence, the notorious bullwhip effect [7] will have a particularly strong influence on the fashion supply chain. Since forecasting is a critical factor relating to the presence and significance of the bullwhip effect, improving forecasting can help reduce the bullwhip 
effect which directly enhances the efficiency of the fashion supply chain.

From the above discussions, it is crystal clear that fashion retail sales forecasting is a truly important topic in practice. Over the past decade, a number of research studies have been reported in the literature. However, each forecasting method has its limits and drawbacks. For example, the traditional statistical methods depend highly on the time series data's features and this will affect the forecasting accuracy a lot. Artificial intelligence (AI) methods can perform better in terms of accuracy than the traditional statistical forecasting models but they usually require a much longer time and a larger requirement on computational power. Thus, many researchers propose to combine multiple methods together to form a new "hybrid method" to achieve an efficient and effective forecasting task.

In this paper, we select and review a set of papers from the literature. In order to have a comprehensive collection of papers, we employ the popular and powerful research portals of http://scholar.google.com/ and http://www.sciencedirect.com/ and search objectively by keywords of "fashion forecasting," "apparel forecasting," "textile forecasting," "clothing forecasting," and other combinations with the keywords of "predict/prediction/forecast" to replace "forecasting." We then filter the searching outcomes and keep the peer-refereed papers which are written in English, together with some papers suggested by reviewers and our own peers, to compile this review paper. Notice that this paper is different from the recently published literature [8] in which they have different focal points. To be specific, [8] mainly discusses different kinds of general methods in relation to the market feature in the fashion industry whereas this paper focuses specifically on exploring and comparing the technical contents of the reviewed analytical models. As a remark, this paper can be viewed as an extension to the previous review paper in [9] with a much more comprehensive review and more in-depth discussions of the topic.

The organization of this paper is given as follows. We review the pure statistical fashion retail sales forecasting methods in Section 2. We discuss the pure AI based fashion retail sales forecasting methods in Section 3. We explore various different forms of hybrid fashion retail sales forecasting methods in Section 4. We investigate the applications of forecasting methods in the fashion retail industry in Section 5. We conclude the paper with a discussion of the evolution of methods as well as the future research directions in Section 6 .

\section{Statistical Fashion Sales Forecasting Methods}

Traditionally, fashion sales forecasting is accomplished by the statistical methods. In fact, a lot of statistical methods have been used for sales forecasting, which include linear regression, moving average, weighted average, exponential smoothing (used when a trend is present but not linear), exponential smoothing with trend, double exponential smoothing, Bayesian analysis, and so forth.
Statistical time series analysis tools such as ARIMA and SARIMA are widely employed in sales forecasting [10]. Since these methods have a closed form expression for forecasting, it is simple and easy to implement and the results can be computed very quickly. In the literature, Green and Harrison [11] apply a Bayesian approach to explore forecasting for a mail order company which sells ladies dresses. After that, Thomassey et al. [12] use item classification to examine the accuracy of sales forecasting for new items. They find that a larger number of item families and pertinent classification criteria are required in the respective forecasting procedure in order to achieve an improved forecasting precision. They conclude that product family and aggregated forecasting are more accurate than the individual item's forecasting. Recently, Mostard et al. [13] also consider the forecasting problem based on a case study of a mail order apparel company. They propose a "top-flop" classification method and argue that it performs better than other methods. Furthermore, they find that the expert judgment methods outperform the advance demand information method for a small group of products. Another recent work [14] examines the applicability of a Bayesian forecasting model for fashion demand forecasting. It is found that the proposed hierarchical Bayesian approach yields superior quantitative results compared to many other methods.

Despite being popularly used for their simplicity and fast speed, it is well known that the statistic methods suffer a few problems. First, the selection of the right statistical methods is an uneasy task. It requires an "expert" knowledge. Second, in terms of performance, they do not usually lead to very promising results. In particular, compared to the more sophisticated methods such as AI methods, statistical models' performance is usually worse. Third, fashion sales are affected by multiple factors such as the fashion trends and seasonality and exhibit a highly irregular pattern [9], which implies that the pure statistical methods may fail to achieve a desirable forecasting outcome.

\section{AI Fashion Retail Sales Forecasting Methods}

As discussed in Section 2, the pure statistical models have deficiency in conducting fashion retail forecasting, in order to improve forecasting accuracy. AI methods emerge with the advance of computer technology. In fact, AI models can efficiently derive "arbitrarily nonlinear" approximation functions directly from the data. Popular methods such as artificial neural network (ANN) models [15] and fuzzy logic models are commonly employed in the literature and they are the first kind of models being employed for fashion retail sales forecasting. To be specific, ANN models have been developed and they provide satisfactory results in different domains [16-18]. In the literature of fashion sales forecasting, Frank et al. [3] explore the use of ANN model for conducting fashion retail sales forecasting. Comparing it with two other statistical methods in terms of forecasting result, it is found that ANN model achieves the best performance. Afterwards, the evolutionary neural network (ENN) model, which is a promising global searching approach for feature and model 
TABLE 1: The summary of AI methods-based fashion retail sales forecasting.

\begin{tabular}{|c|c|c|c|}
\hline Method & Paper & Area & Findings \\
\hline ANN & [3] & Sufficient data & ANN model outperforms the two statistical based models. \\
\hline \multirow{2}{*}{ Fuzzy } & {$[15]$} & $\begin{array}{l}\text { Short term } \\
\text { Sufficient data }\end{array}$ & $\begin{array}{l}\text { Multivariate fuzzy analysis is better compared to that of univariate analysis for } \\
\text { short term forecasting. }\end{array}$ \\
\hline & {$[28]$} & Color & $\begin{array}{l}\text { Fuzzy colour prediction system is better than the traditional approach, but it } \\
\text { only applies to single-colour prediction case. }\end{array}$ \\
\hline ENN & [19] & $\begin{array}{c}\text { Low demand uncertainty and weak } \\
\text { seasonal trends } \\
\text { Short term }\end{array}$ & $\begin{array}{l}\text { Performance of ENN is better than the traditional SARIMA model for } \\
\text { products with features of low demand uncertainty and weak seasonal trends. }\end{array}$ \\
\hline ELM & [31] & $\begin{array}{l}\text { Color, size, and price as significant } \\
\text { factors }\end{array}$ & $\begin{array}{l}\text { ELM outperforms several sales forecasting methods which are based on } \\
\text { backpropagation neural networks. }\end{array}$ \\
\hline EELM & [32] & Fast forecasting & $\begin{array}{l}\text { EELM is versatile in which it can be used for short, medium to long-term } \\
\text { predictions with both time series and non-time series data. }\end{array}$ \\
\hline
\end{tabular}

selection, has been used in fashion sales forecasting. To be specific, Au et al. [19] employ ENN to search for the ideal network structure for a forecasting system, and then an ideal neural networks structure for fashion sales forecasting is developed. They report that the performance of their proposed ENN model is better than the traditional SARIMA model for products with features of low demand uncertainty and weak seasonal trends.

The theory of fuzzy sets is proposed by Zadeh [20] and it has been applied in a lot of areas (e.g., [21-27]). In fashion retail sales forecasting, Sztandera et al. [15] construct a novel multivariate fuzzy model which is based on several important product variables such as color, time, and size. In their proposed model, grouped data and sales values are calculated for each size-class combination. Compared with several statistical models such as Winters' three parameter exponential smoothing model (W3PES), the neural network model, and the univariate forecasting models, they find that their proposed multivariable fuzzy logic model is an effective sales forecasting tool. In fact, the good performance of the fuzzy logic based models comes from their ability to identify nonlinear relationships in the input data. In addition, the multivariate fuzzy logic model performs better in comparison to the univariate counterparts. Later on, Hui et al. [28] explore the demand prediction problem in terms of fashion color forecasting. They propose a fuzzy logic system which integrates preliminary knowledge of colour prediction with the learning-based fuzzy colour prediction system to conduct forecasting. They report several promising results of their proposed method.

Despite the fact that ANN and ENN models perform well in terms of yielding high forecasting accuracy (as indicated by performance measures such as the mean-squared error), these forecasting models require a very long time to complete the forecasting task. In other words, they are very time consuming. The reason behind such a drawback comes from the fact that these models are all utilizing the gradient-based learning algorithms such as the backpropagation neural network (BPNN). To overcome this problem, the extreme learning machine (ELM) based models have emerged. In fact, ELM is known to be a super fast method and it can successfully prevent problems associated with stopping criteria, learning rate, learning epochs, local minima, and the over-tuning from happening. In the literature, ELM has been employed in fashion sales forecasting and its performance is proven to be better than many backpropagation neural networks based methods [29, 30]. Actually, Sun et al. [31] pioneer the use of ELM for sales forecasting in fashion. They investigate the relationship between sales amount and the significant factors which affect demand (e.g., design factors). However, ELM has its most critical drawback of being "unstable" as it can generate different outcome in each different run. To overcome this issue, an extended ELM method (EELM) is proposed in [32] which computes the forecasting result by repeatedly running the ELM for multiple times. Of course, the number of repeating times is an important parameter in EELM and it can be estimated.

Table 1 summarizes the representative papers using pure AI methods for conducting fashion retail sales forecasting.

Even though ELM and EELM are faster than the classical ANN and ENN based forecasting models, they are far from perfect. In particular, ELM is unstable, and EELM still needs a substantial amount of time to conduct prediction. In other words, there are cases in which they might not work well (e.g., EELM with multiple repeated runs of learning machine (LM) cannot complete the forecasting task to be done within any given time constraint imposed by the users [9]). The same applies to other pure statistical and pure AI methods. As a consequence, pinpointing on different perspectives, various hybrid models are developed in the literature to enhance fashion retail sales forecasting.

\section{Hybrid Methods for Fashion Sales Forecasting}

Hybrid forecasting methods are usually developed based on the fact that they can utilize the strengths of different models together to form a new forecasting method. As such, many of them are considered to be more efficient than the pure statistical models and pure AI models. It is not surprising that in recent years, a number of research works examine hybrid forecasting methods, for example, [53, 55-59]. Hybrid methods employed in the fashion forecasting literature often 
combine different schemes such as fuzzy model, ANN, and ELM with other techniques such as statistical models, the grey model (GM), and so forth. In the following, we review the literature on hybrid methods in multiple subsections.

4.1. Fuzzy Logic Based Hybrid Methods. Vroman et al. [33] are the pioneers in studying fuzzy based hybrid fashion forecasting method. They derive a fuzzy-adaptive model which controls the weighting factors of an exponential-smoothing statistical "Holt-Winter" forecasting method. They show that the proposed fuzzy hybrid model outperforms the conventional Holt-Winter method. They also advocate that their proposed method can be applied for new item fashion sales forecasting. After that, Thomassey et al. [34] use fuzzy logic concept to perform fashion forecasting. Their new model allows automatic learning of the nonlinear explanatory variables' influence. Notice that their model requires a subjective expert judgment for the learning process which poses a challenge for its real-world application in the fashion retailing industry. Thomassey et al. [37] propose a forecasting system which is based on multiple models such as fuzzy logic, neural networks, and evolutionary procedures. They argue that the result is versatile in processing the uncertain data. Recently, Yesil et al. [39] apply a hybrid fuzzy model to fast fashion forecasting. To be specific, they combine the fuzzy logic model and the statistical model to conduct forecasting. In their hybrid method, they calculate final forecast for weekly demand based on the weighted average of forecasts that are generated by multiple methods. They argue that their proposed method achieves high accuracy.

4.2. Neural Network Based Hybrid Methods. In neural network (NN) hybrid models, Vroman et al. [40] employ a NN model with corrective coefficients of the seasonality feature for mean-term forecasting horizon. They argue that their proposed hybrid method can also conduct forecasting for short and discontinuous time series. They report good results with their proposed NN hybrid model and believe that the outstanding performance comes from the NN's ability of mapping the nonlinear relation between data inputs and output. Thomassey and Happiette [41] develop a hybrid neural clustering and classification scheme for conducting sales forecasting of new apparel items. Their model can increase the accuracy of midterm forecasting in comparison with the mean sales profile predictor. ANN can also be combined with other techniques like Grey method (GM) and autoregressive technique. For instance, a two-stage dynamic forecasting model, which contains neural network and auto regressive technique, is applied for fashion retail forecasting in $\mathrm{Ni}$ and Fan [43]. In their model, $\mathrm{Ni}$ and Fan use neural network to establish a multivariable error forecasting model. Their model develops the concept of "influence factors" and divides the "impact factors" into two distinct stages (long term and short term). The computational experiment shows that the multivariable error forecasting model can yield good prediction results for fashion retail sales forecasting problems. Aksoy et al. [38] combine the fuzzy method and neural networks to form a new system called the adaptivenetwork based fuzzy inference system. Their proposed new system combines the advantages of both systems, namely, the learning capability of the neural networks and the generalization capability of the fuzzy logic technique, and establishes the hybrid powerful system. Most recently, Choi et al. [44] apply an ANN and GM based hybrid model for fashion sales forecasting with respect to color. They compare ANN, GM, Markov regime switching, and GM+ANN hybrid models. They reveal that the $\mathrm{GM}(1,1)$ and ANN hybrid model is the best one for forecasting fashion sales by colors in the presence of very few historical data.

4.3. ELM Based Hybrid Methods. The extreme learning machine (ELM) is quick in conducting forecasting [45]. Despite the fact that it is not perfect because of its unstable nature, its "fast speed" makes it a very good candidate to be a component model for more advanced hybrid model for fashion forecasting. For example, Wong and Guo [42] propose a novel learning algorithm-based neural network to first generate initial sales forecast and then use a heuristic fine-tuning process to obtain more accurate final sales forecast. Their learning algorithm integrates an improved harmony search algorithm and an extreme learning machine to improve the network generalization performance. They claim that the performance of their proposed model is superior to the traditional ARIMA models and two recently developed neural network models for fashion sales forecasting. Xia et al. [46] examine a forecasting model based on extreme learning machine model with the adaptive metrics. In their model, the inputs can solve the problems of amplitude changing and trend determination, which in turn helps to reduce the effect of the over fitting of networks. Yu et al. [47] use ELM and Grey relational analysis (GRA) to develop a fashion color forecasting hybrid method [47]. Their computational result with real empirical data proves that their proposed model outperforms several other competing models in forecasting fashion color.

4.4. Other Hybrid Methods. In addition to the types of hybrid methods reviewed above, some other innovative forecasting combined methods are also reported in the literature on fashion sales forecasting. For example, Choi et al. [48] employ a hybrid SARIMA wavelet transform (SW) method for fashion sales forecasting. Using real data and artificial data, they show that with relatively weak seasonality and highly variable seasonality factor, their proposed SW method outperforms the classical statistical methods. They conclude to say that the SW method is suitable for conducting volatile demand forecasting in fashion. Thomassey and Fiordaliso [49] develop a hybrid method which is based on an existing clustering technique and a decision tree classifier. Their proposed hybrid method is useful for estimating the sales profiles of new items in fashion retail in which there is no historical sales data. Ni and Fan [43] establish a combined method which includes autoregression and decision tree method (called ART method). They propose that this hybrid 
method performs very well for fashion sales forecasting. Table 2 summarizes the reviewed hybrid methods.

\section{Applications in Fashion Industry}

Sales forecasting is a real-world problem in fashion retailing. From the perspective on applications and implementation, various issues are identified.

First, in terms of the forecasting horizon, most of the existing forecasting models are suitable for middle-term and long-term forecasting. However, short-term forecasting, including the very short term forecasting such as real-time forecasting, is not yet fully explored. This kind of short-term forecasting is very important given the nature of the fashion industry (the fashion trend is unpredictable, and the lead time is very short). From the literature review, we find that the fuzzy logic based technique has been adopted for short-term fashion sales forecasting, the methods [15, 34, 36, 38], and so forth. Thus, we argue that for real-world implementations, fuzzy logic based models, together with other speedy models (such as statistical methods), can be good candidates for realworld implementation as a short-term retail sales forecasting system.

Second, regarding the product type to be forecasted, two kinds of products are involved, namely, the existing product and a new product. Compared to the existing products forecasting, prediction on new product forecasting seems to be much more complicated and difficult, due to the absence of historical sales data. In the current literature, some papers study the new item forecasting (e.g., [60-64]), but very few papers explore the new item forecasting in fashion industry, and exceptions include the following: (i) an item classification method is used in [12], a neural networks and classification combined method is reported in [41], and a fuzzy and Holt Winter hybrid method is examined in [33], and an ANN based hybrid method is proposed in [37]. Obviously, the AI method is used frequently for new item forecasting. It is the case because the AI method can better catch the characteristics of the data and get a more accurate result. Notice that the classification method is applied to new item forecasting for such a reason, too. When predicting a new item, the information and data are very limited. In order to get more information, we have to wisely extract the useful information from the available data. Therefore, a systematic classification scheme is critical for this task.

Third, in terms of speed, in general, statistical methods can output the forecasting results very quickly. AI methods are usually more time consuming. In the past, the lead time in the fashion industry is a bit longer than now, and the lead time can be ten months or even one year. However, the fashion industry has changed and fast fashion companies like ZARA, H\&M, and Mango are adopting quick response strategy with a very short lead time (e.g., 2 weeks in Zara for some products). As a result, forecasting result must be available within a very short time for any forecasting application for these companies. From the reviewed literature, we observe that owing to the high speed of ELM [45], it can be a good candidate to function under "fast fashion forecasting" domain, together with statistical methods. In addition, the fuzzy combiner method can also be used to explore the problem for fast fashion forecasting [39], in which the combiner generates forecasts by combining the forecasts of different methods through fuzzy logic.

\section{Conclusion and Future Research Directions}

In this paper, we have conducted a comprehensive review of the literature on fashion retail sales forecasting. We have explored the advantages and the drawbacks of different kinds of analytical methods for fashion retail sales forecasting. We have also examined the pertinent issues related to real-world applications of the fashion retail sales forecasting models. From the reviewed literature above, we prepare Table 3 which summarizes the fashion forecasting literature with respect to the pure statistical models, the pure AI models, and the hybrid models.

From Table 3, despite being popularly employed in the industry, it is interesting to observe that the pure statistical methods are not popularly studied in the literature over the past 15 years. The reasons are as follows. (i) They are already well-explored, and (ii) they are not sufficient to yield sophisticated forecasting result by themselves. In fact, new studies all move to AI and the hybrid models. The pure AI models are studied a few times over the past 15 years. However, obviously, pure AI (with a single method) models are also not sufficient to generate most accurate forecasting result with respect to the feature of fashion sales forecasting. As a result, the hybrid model based papers appear most frequently, especially over the past four years. Thus, we believe that it is still a timely topic to explore more advanced hybrid models for fashion retail sales forecasting.

Finally, we conclude this paper with the discussions of a few future research directions below.

(1) For fashion retail sales forecasting, regarding the data source, there are three kinds of data, namely, the time series data, cross-section data, and panel data. The time series data, which is collected over discrete intervals of time, is widely used in fashion forecasting and the methods applied to time-series data are also well developed. Cross-section data is collected over sample units in a particular time period and panel data follows individual microunits over time. These two kinds of data are not yet fully used for fashion sales forecasting. Recently, a forecasting method using the panel data is developed in [54] and it will be an interesting future research direction to explore the use of these different types of data for fashion sales forecasting.

(2) Color is one critical element in fashion and it is highly related to the inventory and production planning of fashion apparel products. However, from the reviewed literature, only very few prior studies have examined color forecasting (such as [44, 50$52,65])$. Thus, more studies on this topic can be conducted. In addition, on a related area, no prior study has examined how fashion pattern design and 
TABLE 2: The summary of hybrid methods-based fashion retail sales forecasting models.

\begin{tabular}{|c|c|c|c|c|}
\hline & od & Paper & Domain & Findings \\
\hline \multirow{7}{*}{ Fuzzy } & Holt Winter & {$[33]$} & New items & $\begin{array}{l}\text { The proposed fuzzy-adaptive model controls the weight factors of an } \\
\text { exponential-smoothing forecasting method, and it can be applied to } \\
\text { new item sales forecasting. }\end{array}$ \\
\hline & \multirow[t]{2}{*}{ CCX } & {$[34]$} & Mean term & $\begin{array}{l}\text { It uses fuzzy logic abilities to map the nonlinear influences of } \\
\text { explanatory variables to conduct forecasting, but expert judgment is } \\
\text { required for the learning process. }\end{array}$ \\
\hline & & {$[35]$} & Mean term & $\begin{array}{l}\text { It allows a textile company to obtain mean term forecasting to pass } \\
\text { commands to providers. }\end{array}$ \\
\hline & NN & {$[36]$} & Short term & $\begin{array}{l}\text { The method performs short-term forecasting by readjusting } \\
\text { mean-term model forecasts from load real sales. }\end{array}$ \\
\hline & $\begin{array}{l}\text { Distribution } \\
\text { of aggregated } \\
\text { forecast and } \\
\text { classification }\end{array}$ & {$[37]$} & $\begin{array}{c}\text { New items } \\
\text { Insufficient data }\end{array}$ & $\begin{array}{l}\text { The method (items forecasting model based on distribution of } \\
\text { aggregated forecast and classification) estimates the item sales of the } \\
\text { same family without requiring historical data. }\end{array}$ \\
\hline & NN & {$[38]$} & Short term & $\begin{array}{c}\text { The model promotes greatly the accuracy of forecasting results for the } \\
\text { horizon of one month. }\end{array}$ \\
\hline & NN & [39] & Fast forecasting & $\begin{array}{c}\text { Using fuzzy logic, the combiner calculates final forecast for each } \\
\text { week's demand as a weighted average of forecasts that are generated } \\
\text { by different methods. The combined forecast achieves better accuracy } \\
\text { than any of the individual forecasts. }\end{array}$ \\
\hline \multirow{5}{*}{ ANN } & CCX & {$[40]$} & Mean term & $\begin{array}{l}\text { Considering noisy data and multiple explanatory variables } \\
\text { (controlled, available or not) related to the sales behavior, the } \\
\text { proposed model performs well. }\end{array}$ \\
\hline & Classification & {$[41]$} & New items & $\begin{array}{c}\text { Neural clustering and classification model globally increases the } \\
\text { accuracy of midterm forecasting in comparison with the mean sales } \\
\text { profile predictor. }\end{array}$ \\
\hline & $\begin{array}{l}\text { ELM + } \\
\text { Harmony } \\
\text { search }\end{array}$ & {$[42]$} & Mean term & $\begin{array}{l}\text { The learning algorithm integrates an improved harmony search } \\
\text { algorithm and an extreme learning machine to improve the network } \\
\text { generalization performance and is better than traditional ARIMA } \\
\text { models and two recently developed neural network models in fashion } \\
\text { forecasting. }\end{array}$ \\
\hline & ART & {$[43]$} & $\begin{array}{l}\text { Two stages: } \\
\text { long term and } \\
\text { short term }\end{array}$ & $\begin{array}{l}\text { Combining the ART model the and error forecasting model based on } \\
\text { neural network, an adjustment improving model which can be } \\
\text { applied to the fashion retail forecasting is developed. }\end{array}$ \\
\hline & GM & {$[44]$} & $\begin{array}{c}\text { Color trend } \\
\text { Insufficient data }\end{array}$ & $\begin{array}{l}\text { GM+ANN hybrid models are examined in the domain of color trend } \\
\text { forecasting with a limited amount of historical data. The GM+ANN } \\
\text { hybrid model is the best one for forecasting fashion sales by colors } \\
\text { where only very few historical data is available. }\end{array}$ \\
\hline \multirow{3}{*}{ ELM } & Statistic & {$[45]$} & Fast forecasting & $\begin{array}{l}\text { A comparison with other traditional methods has shown that the } \\
\text { ELM fast forecasting model is quick and effective. }\end{array}$ \\
\hline & Metrics & {$[46]$} & Sufficient data & $\begin{array}{l}\text { The adaptive metrics of inputs can solve the problems of amplitude } \\
\text { changing and trend determination and reduce the effect of the } \\
\text { overfitting of the neural networks. The model outperforms } \\
\text { autoregression (AR), ANN, and ELM models. }\end{array}$ \\
\hline & GRA & {$[47]$} & Color trend & $\begin{array}{l}\text { With real data analysis, the results show that the ANN family models, } \\
\text { especially for ELM with GRA, outperform the other models for } \\
\text { forecasting fashion color trend. }\end{array}$ \\
\hline SARIMA & Wavelet & {$[48]$} & $\begin{array}{c}\text { Highly } \\
\text { volatile sales }\end{array}$ & $\begin{array}{l}\text { For real data with relatively weak seasonality and highly variable } \\
\text { seasonality factor, the SW hybrid model performs well. }\end{array}$ \\
\hline \multirow[b]{2}{*}{ Decision tree } & Clustering & [49] & Mean term & $\begin{array}{l}\text { The proposed model based on existing clustering technique and } \\
\text { decision tree classifier is useful to estimate sales profiles of new items } \\
\text { in the absence of historical sales data. }\end{array}$ \\
\hline & $\begin{array}{l}\text { Auto- } \\
\text { regressive } \\
\text { technique }\end{array}$ & {$[43]$} & Short term & A two-stage dynamic short-term forecasting model is proposed \\
\hline
\end{tabular}


TABLE 3: The evolution of topics over time.

\begin{tabular}{|c|c|c|c|c|c|c|c|c|c|c|c|c|c|c|c|c|}
\hline & 1998 & 1999 & 2000 & 2001 & 2002 & 2003 & 2004 & 2005 & 2006 & 2007 & 2008 & 2009 & 2010 & 2011 & 2012 & 2013 \\
\hline $\begin{array}{l}\text { Pure statistical } \\
\text { models }\end{array}$ & & & & & & {$[12]$} & & & {$[49]$} & & & & & & & {$[14]$} \\
\hline Pure AI models & & & & & & [3] & {$[15]$} & [28] & & & {$[19,31,50]$} & & {$[51,52]$} & & {$[32]$} & \\
\hline Hybrid models & {$[33]$} & & & {$[40]$} & {$[34,35]$} & & & {$[36,37]$} & & {$[41]$} & & & {$[42,53]$} & $\begin{array}{c}{[43,45} \\
48]\end{array}$ & $\begin{array}{l}{[38,39,} \\
46,47]\end{array}$ & {$[44,54]$} \\
\hline
\end{tabular}

other design factors affect demand and the respective sales forecasting mechanism. It is another interesting topic for further studies.

(3) In fashion retail system, the sales of the apparel product are strongly influenced by the calendar factor, for example, holiday. It can be observed easily that the sales in National day's holidays in Hong Kong and Black Friday holidays in the USA will go up very quickly and highly. On one hand, the demands on these specific dates are much more volatile and difficult to predict. On the other hand, the revenue that can be generated during these periods of time can be huge. As a consequence, how to precisely forecast the demand during special dates/events becomes crucial to fashion retailors. This becomes another topic open for future research.

\section{Acknowledgment}

The authors declare that there is no conflict of interests with the companies named in this paper. They also thank the comments by the editor and the two reviewers. TsanMing Choi's research is partially supported by The Hong Kong Polytechnic University's Internal Competitive Research Grant of G-YK71. Chi-Leung Hui's research is partially supported by the GRF project account of B-Q21S and The Hong Kong Polytechnic University's Departmental Research Grant project account of A-PM33.

\section{References}

[1] C.-H. Chiu, T.-M. Choi, and D. Li, "Price wall or war: the pricing strategies for retailers," IEEE Transactions on Systems, Man, and Cybernetics Part A, vol. 39, no. 2, pp. 331-343, 2009.

[2] C.-H. Chiu and T.-M. Choi, "Optimal pricing and stocking decisions for newsvendor problem with value-at-risk consideration," IEEE Transactions on Systems, Man, and Cybernetics Part A, vol. 40, no. 5, pp. 1116-1119, 2010.

[3] C. Frank, A. Garg, A. Raheja, and L. Sztandera, "Forecasting women's apparel sales using mathematical modeling," International Journal of Clothing Science and Technology, vol. 15, no. 2, pp. 107-125, 2003.

[4] T. M. Choi, C. L. Hui, and Y. Yu, Eds., Intelligent Fashion Forecasting Systems: Models and Applications, Springer, New York, NY, USA, 2013.

[5] T.-M. Choi and S. Sethi, "Innovative quick response programs: a review," International Journal of Production Economics, vol. 127, no. 1, pp. 1-12, 2010.
[6] S. Thomassey, "Sales forecasts in clothing industry: the key success factor of the supply chain management," International Journal of Production Economics, vol. 128, no. 2, pp. 470-483, 2010.

[7] H. L. Lee, V. Padmanabhan, and S. Whang, "Information distortion in a supply chain: the bullwhip effect," Management Science, vol. 43, no. 4, pp. 546-558, 1997.

[8] M. E. Nenni, L. Giustiniano, and L. Pirolo, "Demand forecasting in the fashion industry: a review," International Journal of Engineering Business Management, 2013.

[9] T.-M. Choi, C.-L. Hui, and Y. Yu, "Intelligent time series fast forecasting for fashion sales: a research agenda," in Proceedings of the International Conference on Machine Learning and Cybernetics (ICMLC '11), pp. 1010-1014, Guilin, China, July 2011.

[10] G. E. P. Box, G. M. Jenkins, and G. C. Reinsel, Time Series Analysis: Forecasting and Control, Wiley Series in Probability and Statistics, John Wiley \& Sons, Hoboken, NJ, USA, 4th edition, 2008.

[11] M. Green and P. J. Harrison, "Fashion forecasting for a mail order company using a bayesian approach," Operational Research Quarterly, vol. 24, no. 2, pp. 193-205, 1973.

[12] S. Thomassey, M. Happiette, and J. M. Castelain, "Mean-term textile sales forecasting using families and items classification," Studies in Informatics and Control, vol. 12, no. 1, pp. 41-52, 2003.

[13] J. Mostard, R. Teunter, and R. De Koster, "Forecasting demand for single-period products: a case study in the apparel industry," European Journal of Operational Research, vol. 211, no. 1, pp. 139147, 2011.

[14] P. M. Yelland and X. J. Dong, "Forecasting demand for fashion goods: a hierarchical Bayesian approach," in Handbook on Intelligent Fashion Forecasting Systems, 2013.

[15] L. M. Sztandera, C. Frank, and B. Vemulapali, "Predicting women's apparel sales by soft computing," in Proceedings of the 7th International Conference on Artificial Intelligence and Soft Computing (ICAISC '04), pp. 1193-1198, Zakopane, Poland, June 2004.

[16] D. Olson and C. Mossman, "Neural network forecasts of Canadian stock returns using accounting ratios," International Journal of Forecasting, vol. 19, no. 3, pp. 453-465, 2003.

[17] H. Yoo, "Short term load forecasting using a self-supervised adaptive neural network," IEEE Transactions on Power Systems, vol. 14, no. 2, pp. 779-784, 1999.

[18] L. M. Zampighi, C. L. Kavanau, and G. A. Zampighi, "The Kohonen self-organizing map: a tool for the clustering and alignment of single particles imaged using random conical tilt," Journal of Structural Biology, vol. 146, no. 3, pp. 368-380, 2004.

[19] K.-F. Au, T.-M. Choi, and Y. Yu, "Fashion retail forecasting by evolutionary neural networks," International Journal of Production Economics, vol. 114, no. 2, pp. 615-630, 2008.

[20] L. A. Zadeh, "Fuzzy sets," Information and Computation, vol. 8, pp. 338-353, 1965. 
[21] I. Escoda, A. Ortega, A. Sanz, and A. Herms, "Demand forecast by neuro-fuzzy techniques," in Proceedings of the 6th IEEE International Conference on Fussy Systems (FUZZ-IEEE '97), pp. 1381-1386, July 1997.

[22] A. Fiordaliso, "A nonlinear forecasts combination method based on Takagi-Sugeno fuzzy systems," International Journal of Forecasting, vol. 14, no. 3, pp. 367-379, 1998.

[23] T. Chen and M. J. J. Wang, "Forecasting methods using fuzzy concepts," Fuzzy Sets and Systems, vol. 105, no. 3, pp. 339-352, 1999.

[24] P. A. Mastorocostas, J. B. Theocharis, and V. S. Petridis, "A constrained orthogonal least-squares method for generating TSK fuzzy models: application to short-term load forecasting," Fuzzy Sets and Systems, vol. 118, no. 2, pp. 215-233, 2001.

[25] G. Jandaghi, R. Tehrani, D. Hosseinpour, R. Gholipour, and S. A. S. Shadkam, "Application of Fuzzy-neural networks in multi-ahead forecast of stock price," African Journal of Business Management, vol. 4, no. 6, pp. 903-914, 2010.

[26] O. O. Mengi and I. H. Altas, "A fuzzy decision making energy management system for a PV/Wind renewable energy system," in Proceedings of the International Symposium on Innovations in Intelligent Systems and Applications (INISTA '11), pp. 436-440, Istanbul, Turkey, June 2011.

[27] S.-M. Chen and C.-D. Chen, "TAIEX forecasting based on fuzzy time series and fuzzy variation groups," IEEE Transactions on Fuzzy Systems, vol. 19, no. 1, pp. 1-12, 2011.

[28] C.-L. Hui, T.-W. Lau, S.-F. Ng, and C.-C. Chan, "Learningbased fuzzy colour prediction system for more effective apparel design," International Journal of Clothing Science and Technology, vol. 17, no. 5, pp. 335-348, 2005.

[29] G.-B. Huang, Q.-Y. Zhu, and C.-K. Siew, "Extreme learning machine: theory and applications," Neurocomputing, vol. 70, no. 1-3, pp. 489-501, 2006.

[30] Q.-Y. Zhu, A. K. Qin, P. N. Suganthan, and G.-B. Huang, "Evolutionary extreme learning machine," Pattern Recognition, vol. 38, no. 10, pp. 1759-1763, 2005.

[31] Z.-L. Sun, T.-M. Choi, K.-F. Au, and Y. Yu, "Sales forecasting using extreme learning machine with applications in fashion retailing," Decision Support Systems, vol. 46, no. 1, pp. 411-419, 2008.

[32] Y. Yu, T.-M. Choi, and C.-L. Hui, "An intelligent quick prediction algorithm with applications in industrial control and loading problems," IEEE Transactions on Automation Science and Engineering, vol. 9, no. 2, pp. 276-287, 2012.

[33] P. Vroman, M. Happiette, and B. Rabenasolo, "Fuzzy adaptation of the Holt-Winter model for textile sales-forecasting," Journal of the Textile Institute, vol. 89, no. 1, pp. 78-89, 1998.

[34] S. Thomassey, M. Happiette, N. Dewaele, and J. M. Castelain, "A short and mean term forecasting system adapted to textile items' sales," Journal of the Textile Institute Part 1, vol. 93, no. 3, pp. 95-104, 2002.

[35] S. Thomassey, M. Happiette, and J. M. Castelain, "An automatic textile sales forecast using fuzzy treatment of explanatory variables," Journal of Textile and Apparel, Technology and Management, vol. 2, no. 4, pp. 1-12, 2002.

[36] S. Thomassey, M. Happiette, and J. M. Castelain, "A short and mean-term automatic forecasting system-application to textile logistics," European Journal of Operational Research, vol. 161, no. 1, pp. 275-284, 2005.

[37] S. Thomassey, M. Happiette, and J.-M. Castelain, "A global forecasting support system adapted to textile distribution,"
International Journal of Production Economics, vol. 96, no. 1, pp. 81-95, 2005.

[38] A. Aksoy, N. Ozturk, and E. Sucky, "A decision support system for demand forecasting in the clothing industry," International Journal of Clothing Science and Technology, vol. 24, no. 4, pp. 221-236, 2012.

[39] E. Yesil, M. Kaya, and S. Siradag, "Fuzzy forecast combiner design for fast fashion demand forecasting," in Proceedings of the IEEE International Symposium in Innovations in Intelligent Systems and Applications (INISTA '12), pp. 1-5, 2012.

[40] P. Vroman, M. Happiette, and C. Vasseur, "A hybrid neural model for mean-term sales forecasting of textile items," Studies in Informatics and Control, vol. 10, no. 2, pp. 149-168, 2001.

[41] S. Thomassey and M. Happiette, "A neural clustering and classification system for sales forecasting of new apparel items," Applied Soft Computing Journal, vol. 7, no. 4, pp. 1177-1187, 2007.

[42] W. K. Wong and Z. X. Guo, "A hybrid intelligent model for medium-term sales forecasting in fashion retail supply chains using extreme learning machine and harmony search algorithm," International Journal of Production Economics, vol. 128, no. 2, pp. 614-624, 2010.

[43] Y. Ni and F. Fan, "A two-stage dynamic sales forecasting model for the fashion retail," Expert Systems with Applications, vol. 38, no. 3, pp. 1529-1536, 2011.

[44] T.-M. Choi, C.-L. Hui, S.-F. Ng, and Y. Yu, "Color trend forecasting of fashionable products with very few historical data," IEEE Transactions on Systems, Man and Cybernetics Part C, vol. 42, no. 6, pp. 1003-1010, 2012.

[45] Y. Yu, T.-M. Choi, and C.-L. Hui, "An intelligent fast sales forecasting model for fashion products," Expert Systems with Applications, vol. 38, no. 6, pp. 7373-7379, 2011.

[46] M. Xia, Y. C. Zhang, L. G. Weng, and X. L. Ye, "Fashion retailing forecasting based on extreme learning machine with adaptive metrics of inputs," Knowledge-Based Systems, vol. 36, pp. 253259, 2012.

[47] Y. Yu, C.-L. Hui, and T.-M. Choi, "An empirical study of intelligent expert systems on forecasting of fashion color trend," Expert Systems with Applications, vol. 39, no. 4, pp. 4383-4389, 2012.

[48] T.-M. Choi, Y. Yu, and K.-F. Au, "A hybrid SARIMA wavelet transform method for sales forecasting," Decision Support Systems, vol. 51, no. 1, pp. 130-140, 2011.

[49] S. Thomassey and A. Fiordaliso, "A hybrid sales forecasting system based on clustering and decision trees," Decision Support Systems, vol. 42, no. 1, pp. 408-421, 2006.

[50] P. Mello, S. Storari, and B. Valli, "A knowledge-based system for fashion trend forecasting," in New Frontiers in Applied Artificial Intelligence, pp. 425-434, Springer, Berlin, Germany, 2008.

[51] J. J. Lin, P. T. Sun, J. J.-R. Chen, L. J. Wang, H. C. Kuo, and W. G. Kuo, "Applying gray model to predicting trend of textile fashion colors," Journal of the Textile Institute, vol. 101, no. 4, pp. 360$368,2010$.

[52] W. Gu and X. Liu, "Computer-assisted color database for trend forecasting," in Proceedings of the International Conference on Computational Intelligence and Software Engineering (CiSE '10), pp. 1-4, Wuhan, China, December 2010.

[53] Q. Wu, "The hybrid forecasting model based on chaotic mapping, genetic algorithm and support vector machine," Expert Systems with Applications, vol. 37, no. 2, pp. 1776-1783, 2010.

[54] S. Y. Ren, T. M. Choi, and N. Liu, "A hybrid forecasting model of panel data in fashion," Working Paper, 2013. 
[55] P. G. Zhang, "Time series forecasting using a hybrid ARIMA and neural network model," Neurocomputing, vol. 50, pp. 159175, 2003.

[56] A. Sfetsos and C. Siriopoulos, "Time series forecasting with a hybrid clustering scheme and pattern recognition," IEEE Transactions on Systems, Man, and Cybernetics Part A, vol. 34, no. 3, pp. 399-405, 2004.

[57] L. Aburto and R. Weber, "Improved supply chain management based on hybrid demand forecasts," Applied Soft Computing Journal, vol. 7, no. 1, pp. 136-144, 2007.

[58] F. Pan, H. Zhang, and M. Xia, "A hybrid time-series forecasting model using extreme learning machines," in Proceedings of the 2nd International Conference on Intelligent Computing Technology and Automation (ICICTA '09), pp. 933-936, Changsha, China, October 2009.

[59] W. I. Lee, B. Y. Shih, and C. Y. Chen, "A hybrid artificial intelligence sales? Forecasting system in the convenience store industry," Human Factors and Ergonomics in Manufacturing \& Service Industries, vol. 22, no. 3, pp. 188-196, 2012.

[60] W. Dodds, "An application of the Bass model in long-term new product forecasting," Journal of Marketing Research, vol. 10, no. 3, pp. 308-311, 1973.

[61] K. B. Kahn, "An exploratory investigation of new product forecasting practices," Journal of Product Innovation Management, vol. 19, no. 2, pp. 133-143, 2002.

[62] W. W. Moe and P. S. Fader, "Using advance purchase orders to forecast new product sales," Marketing Science, vol. 21, no. 3, pp. 347-364, 2002.

[63] P. S. Fader, B. G. S. Hardie, and C.-Y. Huang, "A dynamic changepoint model for new product sales forecasting," Marketing Science, vol. 23, no. 1, pp. 50-65, 2004.

[64] J. W. Thomas, "New product sales forecasting," Decision Analysis, pp. 1-4, 2009.

[65] L. X. Chang, W. D. Gao, and X. Zhang, "Discussion on fashion color forecasting for textile and fashion industries," Journal of Fiber Bioengineering and Informatics, vol. 2, no. 1, pp. 15-20, 2009. 


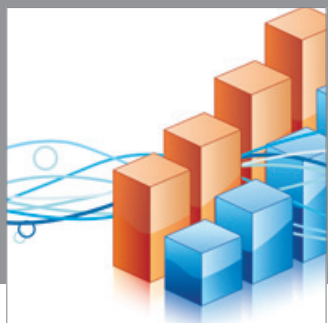

Advances in

Operations Research

mansans

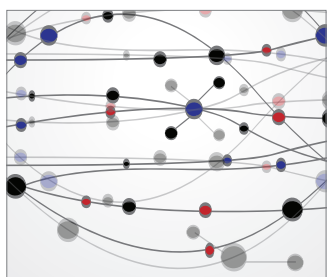

The Scientific World Journal
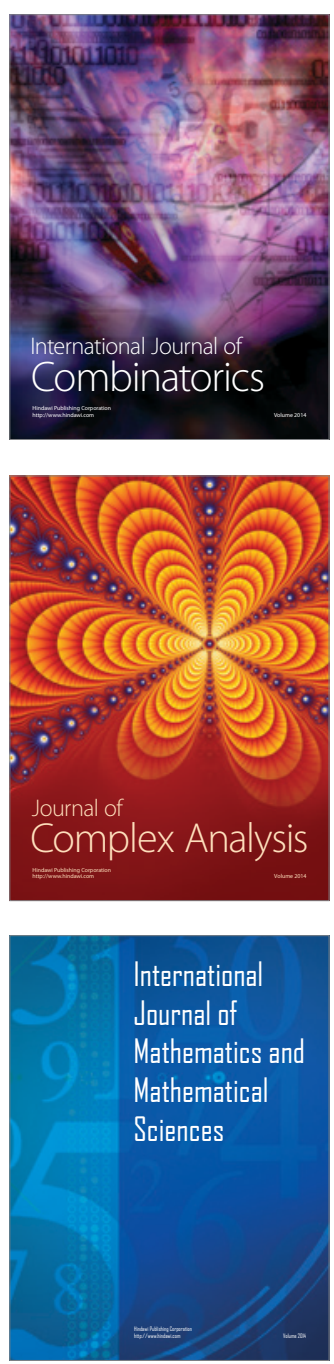
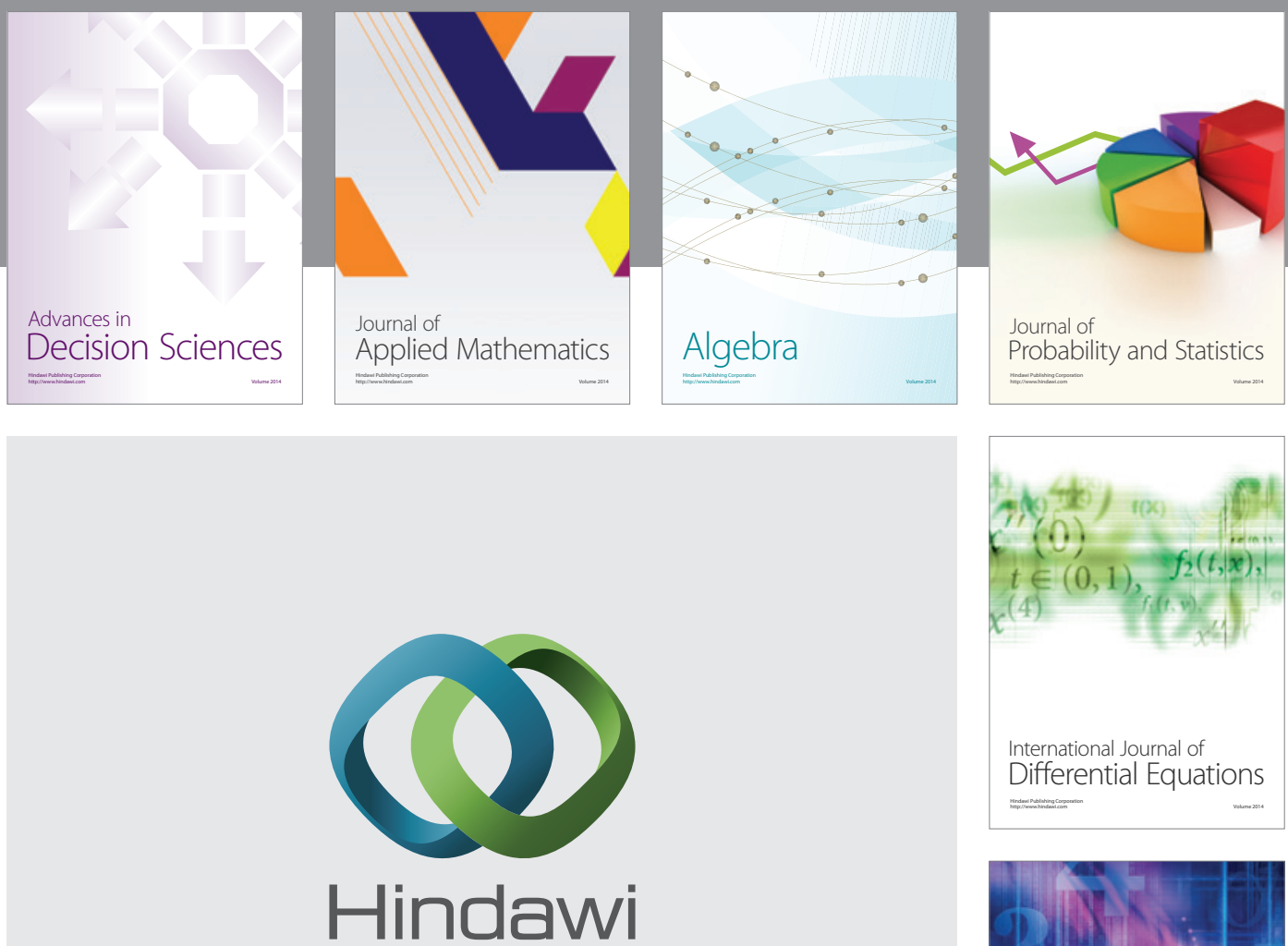

Submit your manuscripts at http://www.hindawi.com
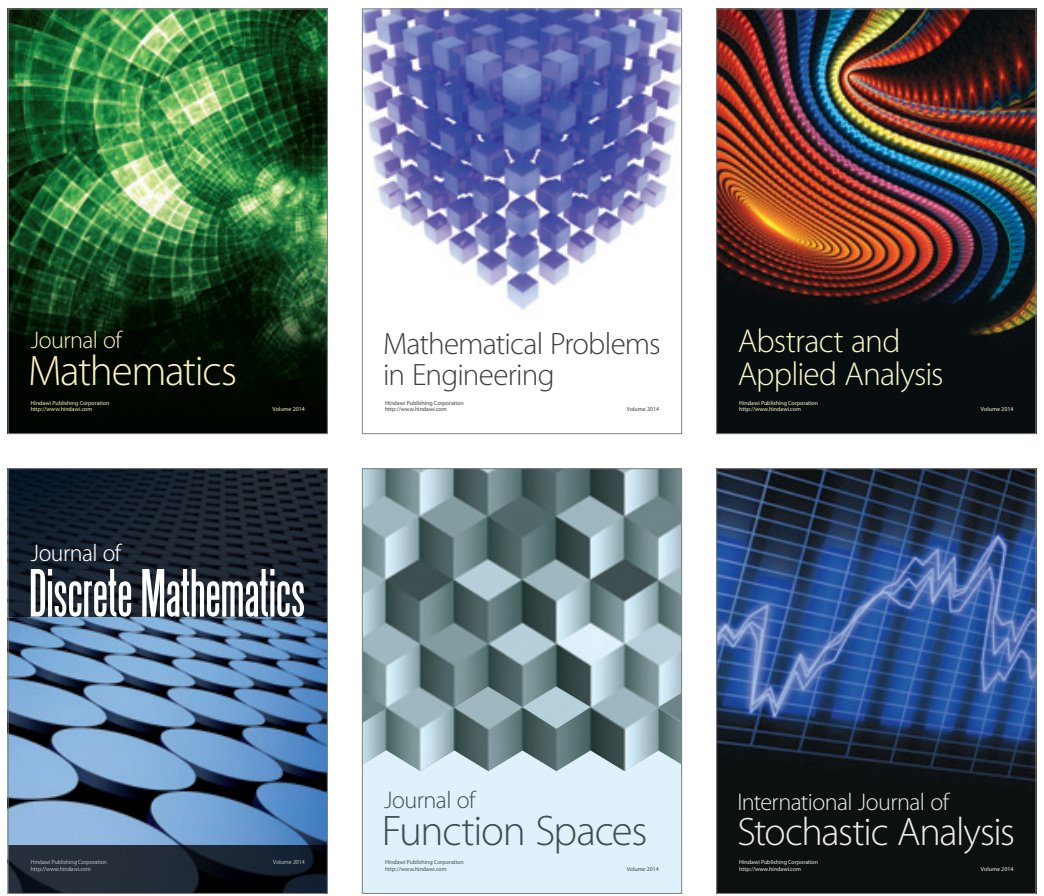

Journal of

Function Spaces

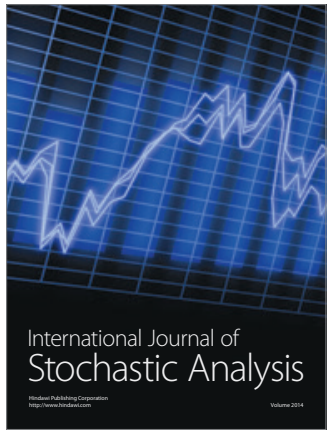

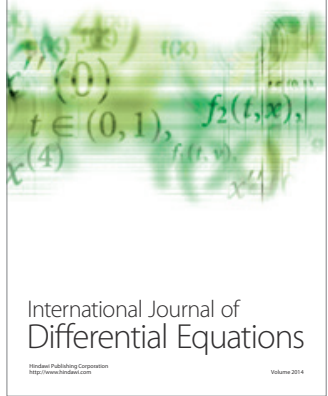
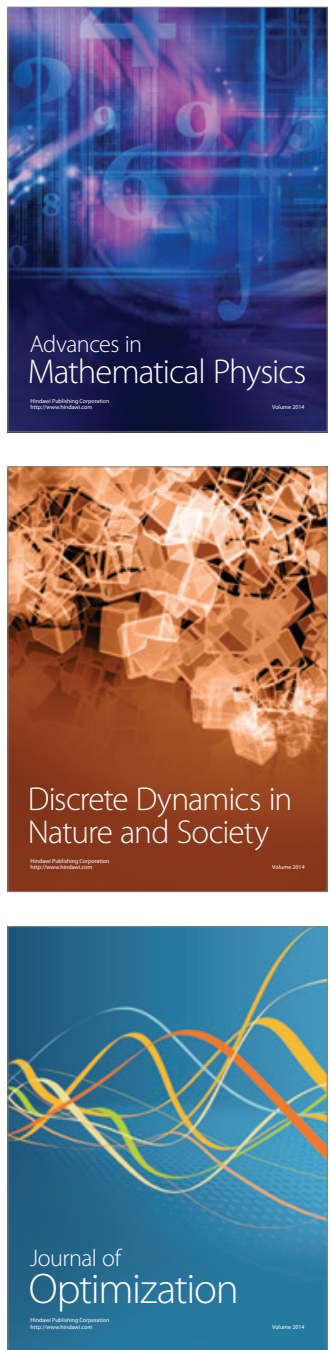